\title{
Socioeconomic Position, Rural Residence, and Marginality Influences on Obesity Status in the Adult Mexican Population
}

\author{
P. Johnelle Sparks and Corey S. Sparks \\ Department of Demography, The University of Texas at San Antonio, 501 West Cesar E Chavez Boulevard, \\ San Antonio, TX 78207, USA \\ Correspondence should be addressed to P. Johnelle Sparks, johnelle.sparks@utsa.edu
}

Received 1 November 2011; Revised 28 February 2012; Accepted 19 March 2012

Academic Editor: Timothy B. Gage

Copyright (๑) 2012 P. J. Sparks and C. S. Sparks. This is an open access article distributed under the Creative Commons Attribution License, which permits unrestricted use, distribution, and reproduction in any medium, provided the original work is properly cited.

\begin{abstract}
This paper assesses individual and social environment determinants of obesity in the adult Mexican population based on socioeconomic position, rural residence, and areal deprivation. Using a nationally representative health and nutrition survey, this analysis considers individual and structural determinants of obesity from a socioeconomic position and health disparities conceptual framework using multilevel logistic regression models. We find that more than thirty percent of Mexican adults were obese in 2006 and that the odds of being obese were strongly associated with an individual's socioeconomic position, gender, place of residence, and the level of marginalization (areal deprivation) in the place of residence. Surprisingly, areas of the country where areal deprivation was highest had lower risks of individual obesity outcomes. We suggest that programs oriented towards addressing the health benefits of traditional food systems over high-energy dense refined foods and sugary beverages be promoted as part of a public health program aimed at curbing the rising obesity prevalence in Mexico.
\end{abstract}

\section{Introduction}

Major improvements in health and economic well-being have occurred over the past several decades in Mexico. However health care expenditures and resources are lower, and major health indicators, such as life expectancy and infant mortality rates, are higher in Mexico compared to other OECD countries [1]. Additionally, obesity prevalence rates are high and increasing in Mexico [2-5], with approximately 30 percent of the adult population obese [6]; only the US has a higher adult obesity rate than Mexico of all OECD countries [1]. Other studies estimate obesity prevalence to be as high as 50 percent of the population [7], and almost 70 percent of the adult Mexican population is either obese or overweight $[6,8]$. Similar obesity prevalence rates have been observed between poor rural and urban adults in Mexico [9]; however gender differences have been noted for overweight and obesity prevalence for Mexican adults indicating a female overweight/obesity disadvantage $[6,7,10]$. The rise in obesity prevalence presents new implications for the health care needs of the Mexican population and longer-term chronic health problems, like diabetes and hypertension $[8$, 11], for a low-income country with high levels of inequality in economic, social service, and health resources [1].

Differences in economic resources, social services, physical infrastructure, health care services, and food environments exist across regions of Mexico [12-14], with noticeable differences in resources and social and physical infrastructures between rural and urban areas of the country [5]. Since uneven development has occurred in Mexico due in part to rapid urbanization and industrialization [15], it is unclear how socioeconomic position (SEP) and the social environments in which people live may influence health outcomes, particularly obesity, for the adult Mexican population in general and in rural and urban areas of the country in particular. This uneven economic and social development and rapid urbanization have occurred concomitantly with a nutrition transition [16-18], which may influence rural/urban or gender obesity differences noted between Mexican adults. Rural Mexican adults are less likely 
to be obese relative to urban adults in Mexico $[6,10]$; however SEP operates differently to influence obesity among rural men and women [19].

Most studies examining the SEP-health relationship in developed and developing countries find that social advantage is associated with better health outcomes [20]. Yet changes to population composition in Mexico due to urbanization, population aging, increased access to educational opportunities, and diversification of economic sectors and employment prospects [21] leave questions about the SEP-obesity relationship for rural and urban residents, particularly when marginality, an areal measure of relative socioeconomic inequality, has increased or remained high for most parts of Mexico [22]. This paper addresses this question by using current nationally representative data for the adult population in Mexico living in both rural and urban areas of the country to examine the SEP-health relationship for obesity status while accounting for individual measures of socioeconomic position and structural measures of marginality.

Borrowing from the segregation and health disparities literature, we argue that a social inequality theoretical perspective offers insight into the SEP-obesity relationship for rural and urban Mexican adults. In particular, we argue that SEP is important for individuals and their health if they are able to translate higher levels of SEP into health promoting behaviors, access to quality and appropriate health care, access to healthy and nutritious foods, and overall safer living environments. Further this perspective would argue that SEP will be less important in determining the obesity status of individuals if the local resources available to the individual, particularly in rural areas, preclude a person from gaining access to health-promoting resources regardless of the SEP of the individual [23]. Therefore we argue that the SEP-obesity relationship in rural areas of Mexico will be weaker than in urban areas as measured by the level of marginality in the individual's municipio of residence.

\section{Socioeconomic Position and Obesity in Mexico}

With population, economic, and social changes occurring in Mexico, it is important to examine the association observed between individual SEP and obesity status for a country experiencing uneven economic growth [21]. Furthermore the mechanisms by which SEP influences obesity status based on rural and urban residence and gender remain less clear, although research has shown that the SEPobesity relationship in Mexico is nonlinear based on rural or urban residence and gender [19]. Pathways most often mentioned in the literature linking SEP to health status more broadly include local environmental conditions of residential location, household and work settings, coping mechanism to deal with stress, health behaviors (including diet and nutrition) and knowledge, and access to appropriate health care $[5,24,25]$. Changes brought about by economic growth and diversification have led to uneven infrastructure development throughout Mexico [12, 14, 21], which may give rural and urban residents different access to healthpromoting resources. Widening social inequalities as measured by area-level deprivation have also remained high in Mexico [22], and the distribution of relative deprivation, measured by the marginality index, across rural and urban areas of Mexico may partially account for differences in SEP-obesity disparities across these types of residential areas. Such relationships between areal-based measures of socioeconomic status, or areal deprivation, and obesity have been seen in other national settings [26-28].

Smith and Goldman [5] offer two plausible explanations for SEP-health disparities that may exist based on residential location in Mexico. First, these authors suggest that increased SEP may provide better access to health-promoting resources, including greater educational opportunities, increased overall knowledge regarding healthy behaviors, safer working and living conditions, enhanced nutrition, and access to appropriate and quality health care services. However access to these resources in rural areas may be much more limited compared to urban areas, and higher levels of SEP may not give an individual better access to these limited resources. Limited access to these health-promoting resources in rural areas may partly be due to differential power structures between rural and urban locations that could result in less power for rural residents in general, but particularly for rural residents living in areas with higher levels of marginality or deprivation. Therefore higher levels of marginality in rural areas may disadvantage the health outcomes of rural residents by decreasing access to important resources and infrastructures necessary to support healthy lifestyles and better health status. Consequently SEP may not have as strong of an association with health outcomes in rural areas since everyone, regardless of SEP, has access to the same set of resources; however rural residents may be further disadvantaged if they live in areas with high marginality.

Second, Smith and Goldman argue that regional differences in cultural practices and quality of education may lead to differences in health-promoting behaviors, which in turn leads to health disparities for urban and rural residents [5]. This point suggests that rural residents may be more limited in adopting certain health behaviors that are found to be protective against obesity if they are unable to purchase healthy and nutritious foods, engage in physical activities beyond those needed for work-related duties, and access appropriate health care in their local environment. Marginality is important in this context because increased levels of area deprivation may make it difficult, if not impossible, for highly marginalized groups to advocate for health, nutrition, and social service resources. We would argue that this does not mean that rural residents are less aware of health-promoting behaviors, but instead are limited in their ability to engage in certain behaviors due to poor infrastructure investment in local areas and limited political power to ensure social and health service availability, regardless of individual levels of SEP.

It is also crucial to consider gender as a key component in the educational disparity that may be present between individuals in rural versus urban areas of Mexico. Again younger cohorts of women in both rural and urban areas 
have increased their levels of education compared to previous birth cohorts [12], but it is not clear that increasing levels of education for younger cohorts of women would produce differences in rates of obesity prevalence by gender for rural or urban women. Research regarding the SEP-obesity relationship based on gender differences indicates mixed results. Some studies find a positive SEP-obesity relationship for men and women [7]; while other research finds that men in middle and high SEP categories have increased odds of being obese compared to men in low SEP categories, but the same is not observed for women $[8,19]$. Research looking at women only finds that obesity prevalence has increased across all SEP groups, measured by living conditions, from 1998 to 2006, but the largest increases have occurred among women in the poorest living conditions [6]. Again the use of different samples and SEP measures leads to less clarity on potential SEP-gender-obesity associations in Mexico. Still we do not think that SEP differentials in obesity will be as strong for women compared to men in Mexico based on limited employment opportunities for women outside of the home in paid labor markets, particularly in rural areas. We also think that gender will be less important in determining SEP-obesity differentials in rural than urban areas based on limited resources in general for both men and women in rural areas.

\section{Methods}

3.1. Data. Two data sources were used for this analysis. First data from the Encuesta Nacional de Salud y NutriciónENSANUT 2006 (National Survey of Health and Nutrition), a nationally representative survey that details the current state of health and nutrition in Mexico for the year 2006, serve as the source of individual level measures for the analysis. This survey is representative of the entire population of Mexico and collects data on the major health problems currently facing the country. The Instituto Nacional de Salud Pública (INSP) was particularly concerned with obtaining data on previously marginalized populations, including indigenous people and people in rural areas from every state in the country. In total, 48,600 households were interviewed based on this sampling design. Further details of the data collection process and household sampling can be found in Olaiz and colleagues [11].

In order to test for structural determinants of individual obesity status, a municipio-level variable was obtained from the Consejo Nacional de Población (National Population Council). Municipios are equivalent to county administrative areas in the United States and are highly variable in size. This area-level unit was selected because municipio indicators were provided for each individual in the ENSANUT, allowing municipio level measures to be merged with individual records.

\subsection{Variable Descriptions}

3.2.1. Individual-Level Variables. Since this paper is an initial investigation of the determinants of adult obesity patterns from a population perspective in Mexico with particular attention given to the SEP-health relationship and potential rural and urban differences, we focus on a dichotomous measure of obesity status as the dependent variable. Obesity status was operationalized by taking a BMI (body mass index) value constructed from data on height (in $\mathrm{cm}$ ) and weight (in $\mathrm{kg}$ ) measurements taken by field personnel for each adult respondent based on a standard set of protocols to assess height and weight [29]. Individuals were assigned to the category obese if their BMI value was equal or greater than 30. Only individuals with reported height and weight measures were included in the analysis, giving a total sample size of 33,498 adults.

Several individual-level predictors were used that contain general information on employment status, educational level, household income, gender, age, rural residence, health behaviors, ethnicity, marital status, and household characteristics. An integral factor to this analysis was rural or urban residence of each respondent. If the respondent lived in a town of less than 2,500 residents, the respondent was identified as a rural resident; otherwise they were identified as an urban resident. This is how rural residence is identified in the ENSANUT.

Sociodemographic variables were used to control for socioeconomic position and basic demographic characteristics that have been traditionally associated with variation in obesity status in the literature in Mexico and other Latin American countries. Two variables were used to capture an individual's SEP, including current employment status and highest level of education completed. Employment status was coded 1 if the individual worked for pay in the last week; if the respondent reported that they had not worked for pay in the last week, this variable was coded 0 . Educational attainment was measured using four dummy variables to indicate the different levels of schooling completed, including no schooling (or less than complete primary school), primary school completed (the reference category), secondary or technical school completed (education beyond secondary school, but less than a university degree), and university education or more completed.

The ENSANUT asked several questions related to indigenous ethnicity, mostly related to whether the individual was able to speak an indigenous language. Responses to the question, "do you consider yourself to be an indigenous person?" were used as a self-reported dichotomous measure of indigenous ethnicity. To examine the relationship between age and obesity, four dummy variables were constructed based on the individual respondent's age and correspond to the following age categories: 20 to 34 (the reference), 35 to 49, 50 to 64 and 65 years of age or older. Age categories were used instead of a continuous measure in order to model possible nonlinear associations between age and obesity status. Gender, a control variable, was coded 1 for males and 0 for females. Marital status was coded to indicate if the respondent was (1) single or never married, (2) divorced or separated, (3) widowed, or (4) married or in a free union (reference category).

Three measures of health behaviors were included in this analysis: walking activity in the last week and current smoking and drinking behaviors. Walking behavior was 
measured using a dummy variable coded as 1 if the respondent answered that they had walked for at least 10 minutes a day for at least three days in the last week and 0 otherwise. Smoking behavior was measured using the answer to the question "do you currently smoke?" If the respondent answered yes, the variable was coded 1, otherwise 0 . Alcohol usage was measured using the response to the question "do you currently drink?" If the respondent answered yes the variable was coded 1 , otherwise 0 . Two variables were also included to control for variation in housing characteristics including if the respondent's house had a dirt floor and if the respondent's house had access to electricity. These were modeled using dummy variables, indicating whether the respondent's house had the corresponding feature.

3.2.2. Structural-Level Variables. Measuring contextual factors related to the social environment is often challenging, and in this analysis a commonly used index of areal disadvantage was used. This index is referred to in the literature as the marginality index for the respondent's municipio. The marginality index is frequently used to assess the level of deprivation in each municipio. This measure has been used by other researchers studying various outcomes in Mexico to access basic access to goods and services and development of an area $[22,30,31]$. The marginality index was constructed using a principle component analysis of eight socioeconomic indicators at the municipio level for the year 2005. This index was obtained from CONAPO for all municipios in Mexico and merged to the individual data file using the municipio of residence for the respondent. The ENSANUT contains observations from 581 of the approximately 2,400 municipios in the country.

3.3. Data Analysis. In order to test for significant differences across individual level variables based on rural or urban residence and gender in this analysis, we first estimated chi-square tests for equal distributions for all variables. We then estimate three multilevel logistic regression models. The first model was specified as a random intercept model with random terms for the municipio of residence and the primary sampling unit. The second model introduces the municipio marginality index measure in addition to the random effects, and the third model includes crosslevel interaction terms between several of the individuallevel predictors and the marginality index. The model specifications are given in the following equations:

$\operatorname{Pr}(Y=1)=\pi$

Model $1: \operatorname{logit}\left(\frac{\pi}{1-\pi}\right)=\alpha_{j k}+\sum_{p} \beta_{p} x_{p}$,

$\alpha_{j k}=\alpha+\alpha_{j}+\alpha_{k}$

$\alpha_{j} \sim N\left(0, \sigma_{j}^{2}\right), \quad \alpha_{k} \sim N\left(0, \sigma_{k}^{2}\right)$

Model $2: \operatorname{logit}\left(\frac{\pi}{1-\pi}\right)=\alpha_{j k}+\sum_{p} \beta_{p} x_{p}+\gamma z_{j}$,

$$
\begin{aligned}
& \alpha_{j k}=\alpha+\alpha_{j}+\alpha_{k} \\
& \alpha_{j} \sim N\left(0, \sigma_{j}^{2}\right), \quad \alpha_{k} \sim N\left(0, \sigma_{k}^{2}\right) \\
& \text { Model 3: } \operatorname{logit}\left(\frac{\pi}{1-\pi}\right)=\alpha_{j k}+\sum_{p} \beta_{p} x_{p}+\gamma z_{j}+\sum \gamma x_{p} * z_{j} \\
& \alpha_{j k}=\alpha+\alpha_{j}+\alpha_{k} \\
& \alpha_{j} \sim N\left(0, \sigma_{j}^{2}\right), \quad \alpha_{k} \sim N\left(0, \sigma_{k}^{2}\right) .
\end{aligned}
$$

Model 1 expresses the log-odds of an individual being obese, $\operatorname{Pr}(Y=1)$, modeled as a function of municipio-level $(j)$ and primary sampling unit $(k)$ random intercepts and the effects of the $p$ individual level covariates. Model 2 again models the log-odds of an individual being obese as a function of the individual level predictors and the municipio level predictor, $z_{j}$, and its effect on the individual log-odds is expressed through the parameter $\gamma$. The intercepts were allowed to vary randomly for each municipio and primary sampling unit, as expressed by the $\alpha_{j k}$ parameter, which is composed of a grand intercept and random deviations for each municipio and sampling unit, each of which is assumed to have a Gaussian distribution with mean of zero and a between-unit variance $\sigma_{k}^{2}$ and $\sigma_{j}^{2}$, respectively. Model 3 was specified much like Model 2, as a multilevel random intercept logistic regression model, except the interaction between some of the individual level predictors $(x)$, and the municipio level predictor $(z)$ was included. These models were estimated using the lme4 library [32] in R 2.14.1 [33]. Since the ENSANUT is a complex survey sample, we adjust our analysis by using the weights provided within the data (variable p_adult). Unfortunately, when using multilevel models, the application of design weights is not always straightforward [34], and we incorporate the design weights at the individual level by scaling the weights to the sum of the primary sampling unit (variable AGEB) population. This can be done arithmetically by

$$
\mathrm{Wt}_{\mathrm{s}}=\mathrm{Wt} *\left(\frac{\# \text { respondents within PSU }}{\Sigma \mathrm{Wt} \text { within PSU }}\right),
$$

where $\mathrm{Wt}$ is the person weight and $\mathrm{Wt}_{\mathrm{s}}$ is the scaled person weight. Results from the analysis are generalizable to the adult Mexican population 20 years of age and older in 2006.

\section{Findings}

4.1. Description of Adult Mexican Population, ENSANUT 2006. Obesity prevalence in the adult Mexican sample in the ENSANUT is similar to other reported information for obesity in this population. Based on the entire ENSANUT adult sample with height and weight measurements $(n=33,498)$, thirty percent of adults were obese. Significant differences exist when examining obesity prevalence by rural/urban residence and gender. Obesity prevalence was higher among urban residents (32.3 percent) compared to rural residents (29.1 percent). Women were more likely to be obese (35.2 percent) compared to men (23.6 percent). 
Almost half of the adult Mexican population was employed during the past week since the time of the interview (47.96 percent). However more urban residents were currently employed in paid labor (50.71 percent) compared to rural residents (38.40 percent). Due to the wide variation of adult age ranges included within the ENSANUT, the distribution of educational levels across all individuals in the full sample was as expected. Significant differences in educational levels did exist between urban and rural residents. More urban residents had completed a secondary education or more (54.77 percent) compared to rural residents (22.15 percent). Almost 20 percent of rural residents had no formal education. Clear statistically significant differences are present in the overall SEP profiles of rural and urban adult residents of Mexico, with rural residents having much less favorable SEP profiles compared to their urban counterparts.

According to the ENSANUT sample with information for height and weight, about 58.66 percent of the Mexican adult population was female and 41.34 percent was male. No differences in the gender distribution were found between rural and urban areas. The majority of the population was between the ages of 20 and 49, yet rural areas of Mexico had a slightly higher proportion of their residents that were 65 years of age or older compared to urban areas. This may partly explain the significant difference in employment status and educational levels noted above between rural and urban residents. Household size was significantly larger in rural areas than in urban areas. Still household size was fairly large in Mexico, with a mean household size of 4.86 persons. Most individuals were single (18.64 percent) or married (70.38 percent). Significant differences exist in the proportion of individuals that were single, married, or divorced between urban and rural areas, with marriage being much more common in rural areas. However no differences exist in the proportion of the population that was widowed between rural or urban areas. No significant differences were noted in physical activity levels, measured by leisure-time walking, for rural or urban residents. Almost 19 percent of adults in Mexico were current smokers and roughly 32 percent of individuals drank alcohol, with urban residents being more likely to both smoke and drink compared to rural residents. Household characteristics differed significantly between rural and urban residents, with rural residents being much more likely to have had a house with a dirt floor (23.21 percent) compared to urban residents (3.95 percent), and rural residents were more likely to have had no electricity (4.72 percent) compared to urban residents ( 0.77 percent).

Gender differences were also present among variables used in this analysis for the adult Mexican population. Women were more likely to be obese than men. Statistically significant differences were found between adult men and women on all three SEP measures. Men were more likely to be currently employed compared to women, 76.86 percent to 27.60 percent, respectively. The distribution of educational levels differed significantly based on gender, with women more likely to have a primary education or less. Marital status differed by gender, with more men being single or married compared to women, while women were more likely to be divorced or widowed compared to men. Men were much more likely to have walked for 10 minutes or more for three days in the last week (79.2\%) compared to women (75.0\%), being current smokers (29.57 percent) or current alcohol consumers (52.41 percent) compared to women (8.85 percent and 18.04 percent, resp.).

Figure 1 presents the spatial distribution of the marginality index at the municipio level in Mexico in 2005. The marginality index also varied greatly across municipios, and statistically significant differences were noted in the marginality index for rural and urban residents in Table 1.

Several regions of the country were characterized by high levels of marginality, indicating high levels of relative deprivation for many areas of Mexico. Specifically municipios in the northwestern, south-central, and south-eastern sections of the country had higher values for this index, while areas along the US border and central Mexico around Mexico City had lower levels of marginalization. This distribution of the marginality index is similar to work done by Peña [31] and reflects patterns of industrial and economic development in different regions of Mexico over the past decade.

4.2. Obesity in Mexican Adults. Table 2 presents results from the regression models for the binary obesity status outcome variable based on the adult ENSANUT sample. Model 1 in Table 2 presents the random effects logistic regression model including only the individual level predictors. Of the individual-level SEP variables, only individuals with a college education or more had lower odds of being obese compared to adults with only a primary education. Compared to females, males experienced a lower risk of obesity, and middle-aged adults faced higher odds of being obese compared to those adults aged 20 to 34 . Rural residents show a significant advantage in terms of obesity status with lower odds of being obese compared to adults in urban areas. Individuals who were identified as being indigenous showed significantly lower odds of being obese compared to nonindigenous individuals, holding other variables in the model constant. Compared to married adults, never-married and widowed individuals showed lower odds of being obese. Two behavioral characteristics were significantly associated with obesity status; these were having walked for more than ten minutes at least three times in the previous week and being a current smoker. When the interaction terms between SEP and rural residence were considered, no significant interactions are found. This indicates that the SEP-obesity relationship does not appear to operate differently based on an individual's residential location. When gender was allowed to interact with SEP, two significant associations were revealed. Males with no formal education had lower odds of being obese compared to females with a primary school education, while males with a college education or more had much higher odds of being obese compared to females with a primary school education.

Model 2 presents the multilevel logistic regression model including the marginalization index at the municipio level and allowed for variance in the model intercept for each municipio and primary sampling unit (random intercepts). With only the marginality index included as a municipio 


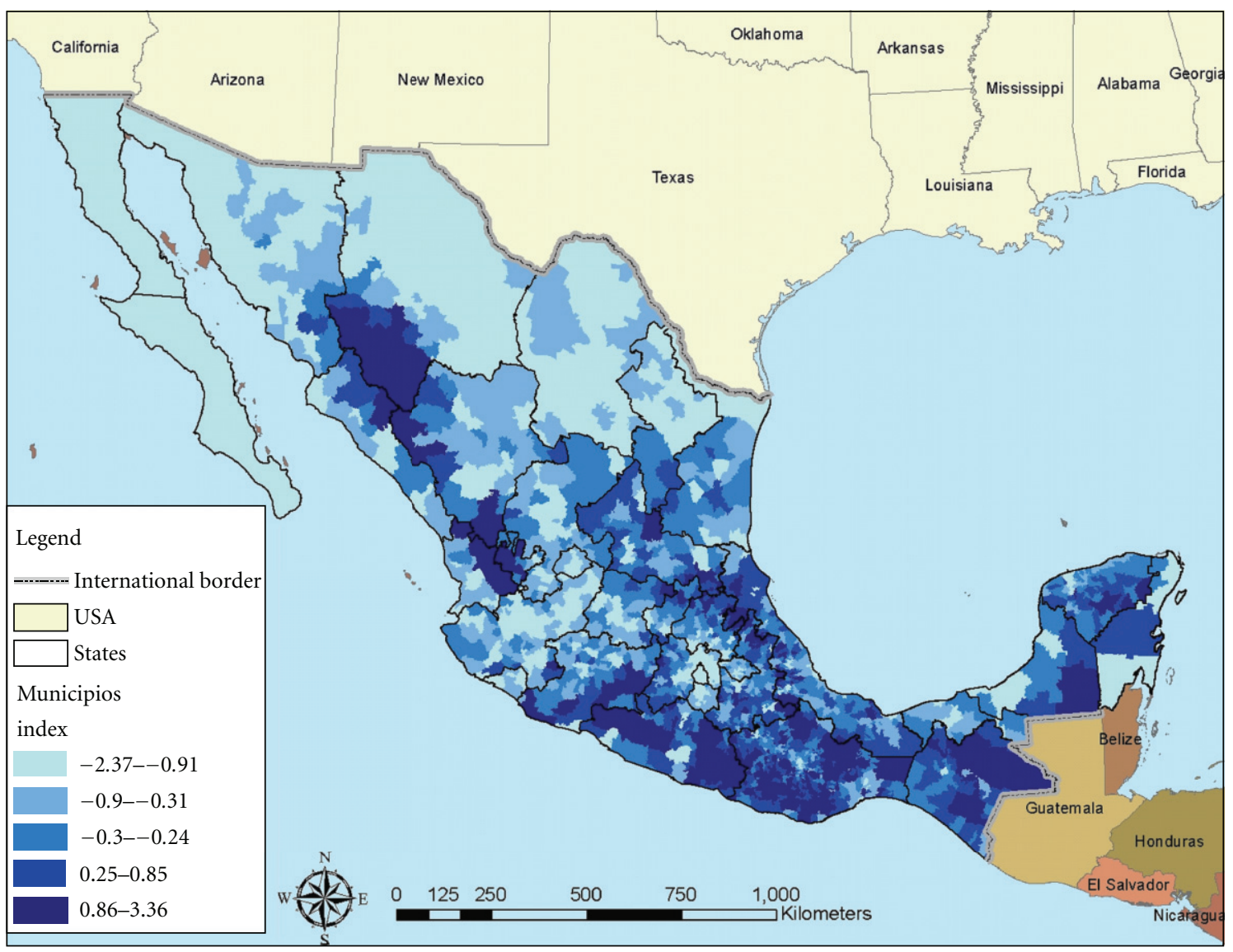

FIGURE 1: Map of geographic distribution of marginality index in mexican municipios, 2005.

level measure in Model 2, significant differences were noted in individual obesity status based on the level of marginality. Stated differently, the level of marginality in a municipio exerts an independent, positive effect on an individual's obesity status even when controlling for appropriate individual level correlates of obesity. This indicates that higher levels of marginality in an area were protective against individual obesity. With respect to the individual-level SEP measures, individuals with a college education or more had lower odds of being obese compared to adults with only a primary education. With respect to the other variables in the model, males experienced a lower risk of obesity compared to females, and middle-aged adults faced higher odds of being obese compared to those adults aged 20 to 34 . Rural residents were at a slight advantage in terms of their lower odds of being obese compared to adults in urban areas. Compared to married adults, all nonmarried individuals showed lower odds of being obese. Two behavioral characteristics were significantly associated with obesity status; these were having walked for more than ten minutes at least three times in the previous week and being a current smoker. Similar associations were noted in the multilevel model when individual interaction terms for rural residence and SEP measures, as well as gender and SEP measures, were included in Model 2 as compared to Model 1. When compared to Model 1, two effects become insignificant in Model 2, indigenous identity and divorced marital status, although the divorce effect's odds ratio stayed exactly the same. Also of note, the rural residence effect in Model 1 was reduced in Model 2 with the inclusion of the marginality index at the municipio level.

Model 3 in Table 2 expands the specification of Model 2 by including the cross-level interaction terms between the individual educational level variables, rural residence, and male gender and the index of marginalization for the municipio. Two significant cross-level interaction terms were observed. First, adults with a secondary or technical education and who live in a municipio with a higher level of marginalization had roughly 12 percent higher odds (95\% CI 1.02-1.22) of being obese than adults with a primary level of education that lived in municipios with an average level of marginalization. This association implies that higher levels of marginalization at the municipio level were more harmful for adults with more education than for those adults with less education. Conversely, a negative association was noted between the cross-level interaction for rural residence and higher levels of marginalization in the individual's municipio. A strong, negative association was still present for the individual level measure for rural residence in this final model, which suggests that rural residents living in areas with higher levels of marginality, or limited access to resources, have more protection against obesity than rural 
TABle 1: Descriptive statistics for obesity status, socioeconomic position, sociodemographic and behavioral characteristics, housing conditions, and the marginality index for the adult mexican population, ENSANUT 2006.

\begin{tabular}{|c|c|c|c|c|c|}
\hline Variables & $\begin{array}{c}\text { Full Sample } \\
(n=33,498)\end{array}$ & $\begin{array}{c}\text { Urban }^{\mathrm{b}} \\
(n=23,825)\end{array}$ & $\begin{array}{c}\text { Rural } \\
(n=9,673)\end{array}$ & $\begin{array}{c}\text { Male }^{c} \\
(n=13,243)\end{array}$ & $\begin{array}{c}\text { Female } \\
(n=20,255)\end{array}$ \\
\hline \multicolumn{6}{|l|}{ Obesity status $(B M I \geq 30)$} \\
\hline \multicolumn{6}{|l|}{ Obese } \\
\hline Yes & 30.4 & $32.1^{* * *}$ & 26.3 & $23.6^{* * *}$ & 35.2 \\
\hline No & 69.6 & 67.8 & 73.6 & 76.3 & 64.8 \\
\hline \multicolumn{6}{|l|}{ Socioeconomic position } \\
\hline Employed & 47.9 & $50.7^{* * *}$ & 38.4 & $76.8^{* * *}$ & 27.5 \\
\hline \multicolumn{6}{|l|}{ Educational level } \\
\hline No education & 10.2 & $7.5^{* * *}$ & 19.8 & $8.3^{* * *}$ & 11.5 \\
\hline Primary education & 42.2 & $37.7^{* * *}$ & 58.0 & $39.7^{* * *}$ & 43.9 \\
\hline Secondary or technical education & 38.7 & $43.7^{* * *}$ & 21.2 & $40.3^{*}$ & 37.6 \\
\hline College education or more & 8.7 & $10.9^{* * *}$ & 0.9 & $11.5^{* * *}$ & 6.7 \\
\hline \multicolumn{6}{|l|}{ Sociodemographic characteristics } \\
\hline \multicolumn{6}{|l|}{ Gender } \\
\hline Male & 41.3 & 41.4 & 41.0 & - & - \\
\hline Female & 58.6 & 58.5 & 58.9 & - & - \\
\hline \multicolumn{6}{|l|}{ Age } \\
\hline $20-34$ & 36.7 & $37.3^{* *}$ & 34.8 & 36.0 & 37.3 \\
\hline $35-49$ & 32.3 & 32.2 & 32.6 & $31.0^{* *}$ & 33.2 \\
\hline $50-64$ & 18.8 & 18.7 & 19.2 & $20.0^{* *}$ & 18.0 \\
\hline 65 or older & 12.0 & $11.6^{* *}$ & 13.2 & $12.8^{*}$ & 11.4 \\
\hline \multicolumn{6}{|l|}{ Residential status } \\
\hline Rural & 22.3 & - & - & 22.4 & 22.1 \\
\hline Urban & 77.6 & - & - & 77.5 & 77.8 \\
\hline Household size (mean) ${ }^{\mathrm{a}}$ & 4.8 & $4.8^{* *}$ & 4.9 & 4.8 & 4.8 \\
\hline Indigenous identity & 18.6 & $15.6^{* * *}$ & 33.5 & $18.9^{\dagger}$ & 20.1 \\
\hline \multicolumn{6}{|l|}{ Marital status } \\
\hline Single (never married) & 18.6 & $20.1^{* * *}$ & 13.4 & $20.1^{* *}$ & 17.5 \\
\hline Married or cohabiting & 70.3 & $68.4^{* * *}$ & 76.9 & $74.7^{* * *}$ & 67.3 \\
\hline Divorced & 4.8 & $5.3^{* * *}$ & 3.1 & $2.4^{* * *}$ & 6.5 \\
\hline Widowed & 6.1 & 6.0 & 6.5 & $2.6^{* * *}$ & 8.6 \\
\hline \multicolumn{6}{|l|}{ Behavioral characteristics } \\
\hline Walked $>3$ days last week & 76.8 & 76.9 & 76.8 & $79.2^{* * *}$ & 75.0 \\
\hline Current smoker & 17.4 & $19.4^{* * *}$ & 10.3 & $29.5^{* * *}$ & 8.8 \\
\hline Currently drinks alcohol & 32.2 & $33.8^{* * *}$ & 26.7 & $52.4^{* * *}$ & 18.0 \\
\hline \multicolumn{6}{|l|}{ Housing conditions } \\
\hline House has dirt floor & 8.2 & $3.9^{* * *}$ & 23.2 & 8.1 & 8.3 \\
\hline House has no electricity & 1.6 & $0.7^{* * *}$ & 4.7 & 1.6 & 1.6 \\
\hline \multicolumn{6}{|l|}{ Municipio level } \\
\hline Marginality Index 2005 & -1.01 & $-1.31^{* * *}$ & -0.20 & -1.04 & -1.00 \\
\hline
\end{tabular}

Values weighted by P_ADULT; $n$ in each column is based on survey sample sizes.

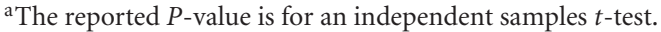

${ }^{b}$ The reported $P$-values are for a chi-square test testing equality of the distribution across rural and urban locations.

${ }^{c}$ The reported $P$-values are for a chi-square test testing equality of the distribution across male and female sexes.

${ }^{\dagger} P=.10,{ }^{*} P=0.05,{ }^{* *} P=0.01,{ }^{* * *} P=0.001$. 
TABLE 2: Results of multilevel models of individual obesity outcome.

\begin{tabular}{|c|c|c|c|}
\hline & $\begin{array}{l}\text { Model 1-random } \\
\text { intercept model }\end{array}$ & $\begin{array}{l}\text { Model 2-multilevel } \\
\text { model }\end{array}$ & $\begin{array}{l}\text { Model 3-multilevel } \\
\text { model with } \\
\text { cross-level } \\
\text { interactions }\end{array}$ \\
\hline Variables & OR $(95 \% \mathrm{CI})$ & OR (95\% CI) & OR $(95 \%$ CI $)$ \\
\hline \multicolumn{4}{|l|}{ Municipio level characteristics } \\
\hline Index of marginalization (IM) & 一 & $0.82(0.78-0.87)^{* * *}$ & $0.87(0.81-0.94)^{* * *}$ \\
\hline \multicolumn{4}{|l|}{ Cross-level interaction terms } \\
\hline $\mathrm{IM}^{*}$ no education & - & - & $0.92(0.84-1.02)$ \\
\hline $\mathrm{IM}^{*}$ secondary/technical education & - & - & $1.12(1.02-1.22)^{*}$ \\
\hline $\mathrm{IM}^{*}$ college education or more & - & - & $1.16(0.97-1.37)$ \\
\hline $\mathrm{IM}^{*}$ male gender & - & - & $1.02(0.96-1.09)$ \\
\hline IM*rural residence & - & - & $0.85(0.78-0.93)^{* * *}$ \\
\hline \multicolumn{4}{|l|}{ Individual level characteristics } \\
\hline \multicolumn{4}{|l|}{ Socioeconomic position } \\
\hline Employed & $0.96(0.92-1.03)$ & $0.95(0.90-1.02)$ & $0.95(0.90-1.01)$ \\
\hline \multicolumn{4}{|l|}{ Educational level } \\
\hline No education & $1.00(0.93-1.14)$ & $1.02(0.91-1.16)$ & $0.95(0.81-1.11)$ \\
\hline Primary education (Ref) & 1 & 1 & 1 \\
\hline Secondary/technical education & $0.93(0.93-1.00)$ & $0.92(0.85-1.00)$ & $1.07(0.93-1.24)$ \\
\hline College education or more & $0.54(0.44-0.59)^{* * *}$ & $0.53(0.46-0.62)^{* * *}$ & $0.66(0.49-0.88)^{*}$ \\
\hline \multicolumn{4}{|l|}{ Sociodemographic characteristics } \\
\hline \multicolumn{4}{|l|}{ Gender } \\
\hline Male & $0.56(0.51-0.61)^{* * *}$ & $0.56(0.52-0.61)^{* * *}$ & $0.58(0.52-0.64)^{* * *}$ \\
\hline Female (Ref) & 1 & 1 & 1 \\
\hline \multicolumn{4}{|l|}{ Age } \\
\hline 20-34 (Ref) & 1 & 1 & 1 \\
\hline $35-49$ & $1.86(1.75-1.94)^{* * *}$ & $1.86(1.75-1.98)^{* * *}$ & $1.86(1.75-1.98)^{* * *}$ \\
\hline $50-64$ & $2.00(1.89-2.11)^{* * *}$ & $1.99(1.85-2.15)^{* * *}$ & $2(1.85-2.15)^{* * *}$ \\
\hline 65 or older & $0.99(0.89-1.08)$ & $0.98(0.88-1.09)$ & $0.98(0.88-1.08)$ \\
\hline Household size & $0.99(0.98-1.00)$ & $0.99(0.98-1)$ & $0.99(0.98-1.00)$ \\
\hline \multicolumn{4}{|l|}{ Residential status } \\
\hline Rural & $0.80(0.76-0.87)^{* * *}$ & $0.91(0.83-1.00)^{*}$ & $0.82(0.73-0.92)^{* * *}$ \\
\hline Urban (Ref) & 1 & 1 & 1 \\
\hline Indigenous identity & $0.93(0.89-1.00)^{*}$ & $0.97(0.91-1.04)$ & $0.98(0.91-1.04)$ \\
\hline \multicolumn{4}{|l|}{ Marital status } \\
\hline Single (never married) & $0.71(.065-0.75)^{* * *}$ & $0.71(0.65-0.76)^{* * *}$ & $0.7(0.65-0.76)^{* * *}$ \\
\hline Married or cohabiting (Ref) & 1 & 1 & 1 \\
\hline Divorced & $0.89(0.81-1.00)$ & $0.89(0.79-1.00)^{*}$ & $0.89(0.79-0.99)^{*}$ \\
\hline Widowed & $0.88(0.81-0.97)^{*}$ & $0.88(0.79-0.99)^{*}$ & $0.88(0.79-0.99)^{*}$ \\
\hline \multicolumn{4}{|l|}{ Behavioral characteristics } \\
\hline Walked $>3$ days last week & $0.76(0.73-0.81)^{* * *}$ & $0.76(0.72-0.81)^{* * *}$ & $0.76(0.72-0.81)^{* * *}$ \\
\hline Current smoker & $0.84(0.78-0.89)^{* * *}$ & $0.83(0.77-0.89)^{* * *}$ & $0.83(0.77-0.90)^{* * *}$ \\
\hline Currently drinks alcohol & $1.03(0.98-1.10)$ & $1.03(0.97-1.09)$ & $1.03(0.97-1.09)$ \\
\hline \multicolumn{4}{|l|}{ Housing conditions } \\
\hline House has dirt floor & $0.74(0.69-0.83)^{* * *}$ & $0.78(0.7-0.86)^{* * *}$ & $0.79(0.71-0.87)^{* * *}$ \\
\hline House has no electricity & $0.67(0.53-0.85)^{* * *}$ & $0.71(0.57-0.88)^{*}$ & $0.73(0.59-0.91)^{* *}$ \\
\hline
\end{tabular}


Table 2: Continued.

\begin{tabular}{llll}
\hline & $\begin{array}{l}\text { Model 1-random } \\
\text { intercept model }\end{array}$ & $\begin{array}{l}\text { Model 2-multilevel } \\
\text { model }\end{array}$ & $\begin{array}{l}\text { Model 3-multilevel } \\
\text { model with } \\
\text { cross-level } \\
\text { interactions }\end{array}$ \\
\hline $\begin{array}{l}\text { Individual-level interactions } \\
\text { Rural*no education }\end{array}$ & $0.85(0.72-0.98)$ & $0.86(0.73-1.03)$ & $0.96(0.79-1.17)$ \\
Rural*secondary/technical Education & $1.15(1.00-1.34)$ & $1.13(0.97-1.31)$ & $1.02(0.86-1.2)$ \\
Rural*college education or more & $1.18(0.73-1.67)$ & $1.15(0.68-1.96)$ & $0.99(0.58-1.72)$ \\
Male*no education & $0.66(0.55-0.80)^{* * *}$ & $0.66(0.54-0.8)^{* * *}$ & $0.64(0.53-0.78)^{* * *}$ \\
Male* secondary/technical education & $1.04(0.90-1.17)$ & $1.04(0.92-1.19)$ & $1.05(0.93-1.2)$ \\
Male* college education or more & $2.08(1.75-2.67)^{* * *}$ & $2.08(1.7-2.54)^{* * *}$ & $2.09(1.7-2.56)^{* * *}$ \\
\hline$\sigma^{2}($ Municipio) & 0.11 & 0.11 & 0.10 \\
$\sigma^{2}$ (PSU) & 0.06 & 0.05 & 0.05 \\
\hline AIC & 38984.4 & 38931.7 & 38913.7 \\
\hline
\end{tabular}

Analysis weighted by P_ADULT. Results are from the entire adult ENSANUT 2006 sample, $n=33,498$. Numbers in parentheses are confidence intervals. ${ }^{*} P \leq 0.05,{ }^{* * *} P \leq 0.001$.

residents that live in municipios with moderate or low levels of marginalization. Further, rural adults that live in areas with higher levels of marginalization have much reduced odds of being obese compared to urban adults in areas with higher levels of marginalization. The other effects at the individual level discussed in Model 2 are consistent in Model 3 . When the three models are compared, Model 3 had lower levels of between municipio and between PSU variance, and a lower AIC than either Models 1 or 2, suggesting a more adequate model fit for the more complex Model 3.

\section{Discussion and Conclusion}

The purpose of this paper has been to explore the SEPobesity relationship for the adult Mexican population based on current population-based data, with special attention given to rural residence and gender. Further this paper assessed potential differences in individual obesity status between municipios while assessing the level of marginality within the municipio. Specifically we explored a measure of obesity status contained in the ENSANUT 2006 by accounting for appropriate individual level characteristics and merging the individual level data with an area-level measure of marginality, or relative deprivation, from CONAPO for the year 2005.

Based on previous research and the theoretical arguments made in the social inequality literature highlighted above, we argued that the potential SEP-obesity relationship should not be as strong for rural residents compared to urban residents. Further, literature highlighting the importance of area-level deprivation on the potential individual SEPhealth association more broadly [22] motivated the use of multilevel statistical models to assess how marginality of an area may operate differently to influence individual obesity status based on individual levels of SEP, rural residence, or gender. In order to test the SEP-obesity relationship among adults in Mexico with potential differences based on rural residence and gender, we estimated logistic regression models, in which the results are generalizable to the adult Mexican population over the age of 20 in 2006. We then included interaction terms in our statistical models for rural residential status and gender and each of the SEP measures in order to test specific hypotheses based on the three main theoretical arguments presented above. Further results from the multilevel statistical models were discussed to situate the cross-level interactive effects noted between individual educational status, rural residence, and municipio marginality on individual obesity status as they relate to changes occurring in Mexico relative to the nutrition transition. First, wide variation in the measures of SEP used in this analysis was noted between rural and urban residents and men and women for the adult Mexican population in the bivariate results. In general, rural residents and women were at an SEP disadvantage relative to men. When examining obesity prevalence based on residential location and gender, we found very similar values to other national studies on obesity prevalence. Urban residents had higher obesity prevalence rates than rural residents, while women were more likely to be obese than men [6]. And while this study only examined whether individuals were obese, meaning an individual who had a BMI $\geq 30$, over 32 percent of Mexican adults 20 years of age or over in this sample were obese, and roughly 67 percent of adults were overweight or obese. These very high prevalence rates of overweight and obesity in Mexico warrant this population-based analysis.

Second, only one of the SEP measures had a statistically significant association with the obesity status outcome in the individual-level logistic regression models. An inverse U-shaped association was noted between educational levels and obesity status in the logistic regression models, which differs somewhat from other research that finds obesity being much more concentrated among lower SEP groups in Mexico $[35,36]$. A similar association found in this analysis has been 
noted between level of education completed and BMI among low-income Mexican adults [7]. Fernald argues that this obesity-education pattern in Mexico may exist for different reasons when examining individuals with high versus low levels of education. Individuals with low levels of education may not have the ability to procure resources that would lead to diets that would increase the risk of overweight or obesity, while individuals with high levels of education likely have the knowledge and resources to eat a more balanced diet that can sustain a healthy weight.

We think that educational attainment may serve as the key underlying mechanism to understand the SEPobesity relationship, because higher levels of education could provide adults access to health-promoting resources, knowledge about healthy and nutritious diets, and the ability to maintain healthy behaviors over time. Results from Model 1 in Table 2 would indicate that rural residents experience more protection from higher or lower levels of education compared to urban residents, indicating that the SEP-obesity relationship holds for rural residents and is not weaker as discussed by Smith and Goldman [5] in the first point made in the introduction. However, the significant interaction terms noted between rural residence and higher levels of education and male gender and higher levels of education may indicate that as adults in Mexico obtain higher levels of education, this may translate into better earnings or jobs that would provide access to a variety of food and beverage choices. More economic resources available to rural residents and men with higher levels of education may mean that these individuals are purchasing foods high in fat, protein, and carbohydrates and/or drinks high in sugar or alcoholic drinks which could lead to an energy imbalance, thus increasing their risk for obesity [10, 37]. However, studies of nutrient intake in the Mexican population find that low SEP individuals and rural residents are consuming more carbohydrates than necessary and not consuming enough good fat which may change the SEP-obesity association among Mexican adults [10]. Cheap, easily available sugary drinks may also present calorie imbalances for low SEP individuals and could lead to higher obesity prevalence among this population $[17,38-40]$. This idea is discussed more fully below as it related to results from the multilevel results.

Additional research on food consumption patterns finds that rural and urban residents purchase and consume similar types of food; however urban residents purchase foods in higher quantities [17]. These authors also find that fruits, vegetables, legumes, meat, eggs, and milk are purchased at a higher rate in Mexico City, which might indicate more healthy and traditional diets for urban residents. On the other hand, refined carbohydrates and sugars are also purchased at a higher rate in this major city and northern parts of Mexico [17]. Most diets in these regions also consist of more fat [18]. These discrepancies in types of foods purchased and consumed in major urban areas and the Northern states of Mexico may partially account for the interactive effects noted between higher levels of education and increased obesity risks for rural residents and men. The increase in sedentary lifestyles across Mexico in conjunction with changing dietary patterns $[41,42]$ raises serious public health concerns that require programs and policies targeted at the appropriate subgroups experiencing increasing and continued high rates of obesity.

Third, an interesting association was noted in the multilevel logistic regression models in that an independent negative association was noted between the level of marginality in a respondent's municipio and their risk of being obese. The negative association indicates that areas with higher levels of area deprivation have a protective effect against obesity for individual residents in these municipios. While this measure has not been examined in other studies looking at obesity as an outcome based on our knowledge, research has shown that area-level marginality increases the odds that individual will report their health as poor in Mexico [22]. Most research examining the association between social inequalities, operationalized as the marginality index, and health outcomes would indicate that higher levels of social inequality, or deprivation, should be harmful for an individual's health [43-45]. Yet our results indicate that marginalization in an area may not lead to higher odds of obesity for individuals living in areas with higher levels of inequality.

The more interesting association in the multilevel models was noted between the cross-level interaction between rural residence for a respondent and higher levels of municipio marginalization. Rural residents living in municipios with higher levels of marginality had much lower odds of being obese than rural residents living in municipios with moderate or lower levels of marginality. We think this association is noteworthy and potentially speaks to the ability of rural residents to maintain more traditional diets in areas of Mexico that experience higher levels of marginality. If more marginalized areas have less access to grocery or convenience stores to purchase less healthy foods [16], residents of these areas will have to eat more traditional diets that have been associated with healthier weights. Less access to processed foods and foods high in refined carbohydrates and sugars may work to protect rural individuals living in highly marginalized areas from obesity. However the emergence of relatively inexpensive, high-energy dense foods throughout Mexico [42] may threaten the more healthy diets and lifestyles of some rural residents. More research is needed to examine the association between area marginalization and obesity for the Mexican population that controls for simultaneous changes being made the economic and food systems throughout the country with particular attention given to the types of food consumed and food preparation techniques. More research on these topics is warranted to fully understand how nutritional transitions influence patterns of obesity in Mexico. Programs are also needed to address the potential role that social inequalities may play in fostering poor food environments and then recommending avenues to provide healthy and reasonably priced foods for more vulnerable population groups in Mexico.

And while this research was specifically interested in the SEP-obesity relationship in the adult Mexican population living in Mexico, we think it is important from a policy and public health perspective to consider the impact migration 
has had and will continue to have on issues of overweight and obesity for Mexican-Americans in the United States. Research on Mexican-Americans in the United States finds that low socioeconomic status and acculturation are associated with increased odds of obesity [46-53]. Differences noted in rural-urban and gender patterns of obesity in this research and other research noting poor diets for residents of the northern Mexican states [17] raise concerns about the most effective way to address the broader health care needs of a highly mobile population. Future research should consider the common health concern that overweight and obesity presents for the populations of both Mexico and the United States, and health and social service programs designed to serve the needs of migrants should address healthy diets and exercise as one way to address rising obesity rates in both of these countries.

\section{Limitations}

We must note limitations to this research. First, we only included adults in this analysis that had reported height and weight in the data file. We decided to not use an imputation method to assign obesity status to those individuals without this information in order not to bias potential associations that might be observed. Tests were performed to see if the individuals with reported height and weight differed from those individuals with this information, and there were some significant differences on certain variables in the analysis. However, we feel confident that we are offering a conservative estimate of the potential associations between rural residence, gender, SEP, and obesity. Further, ENSANUT offers the most current data source on the Mexican population, and this was the best possible measure of obesity status that could be generalizable to the adult population.

Second, our analysis was based on cross-sectional data and included a wide range of adult ages. It is hard to tease out possible cohort effects that may be present in the SEP-obesity relationship modeled here, even though we allow age to be controlled in a nonlinear fashion in our empirical models. More attention to life course perspectives as they relate to the SEP-obesity relationship will be important to future studies examining overweight and obesity in the adult Mexican population to see how SEP may operate differently on health outcomes at different ages of a person's life. Additionally the cross-sectional nature of the data does not allow us to establish causality in associations noted here.

\section{References}

[1] OECD, 2009, OECD Health Data 2009: How Does Mexico Compare, http://www.oecd.org/dataoecd/46/9/38980018.pdf.

[2] L. C. Fernald, X. Hou, and P. J. Gertler, "Oportunidades program participation and body mass index, blood pressure, and self-reported health in Mexican adults," Preventing Chronic Disease, vol. 5, no. 3, p. A81, 2008.

[3] R. M. Malina, M. E. Peña Reyes, S. K. Tan, P. H. Buschang, and B. B. Little, "Overweight and obesity in a rural amerindian population in Oaxaca, Southern Mexico, 1968-2000," American Journal of Human Biology, vol. 19, no. 5, pp. 711-721, 2007.
[4] L. Ruiz-Arregui, L. Castillo-Martínez, A. Orea-Tejeda, S. Mejía-Arango, and A. Miguel-Jaimes, "Prevalence of selfreported overweight-obesity and its association with socioeconomic and health factors among older Mexican adults," Salud Publica de Mexico, vol. 49, supplment 4, pp. S482-S487, 2007.

[5] K. V. Smith and N. Goldman, "Socioeconomic differences in health among older adults in Mexico," Social Science and Medicine, vol. 65, no. 7, pp. 1372-1385, 2007.

[6] J. A. Rivera, L. M. Irizarry, and T. Gonzalez-de Cossio, "Overview of the nutritional status of the Mexican population in the last two decades," Salud Publica de Mexico, vol. 51, supplment 4, pp. S645-S656, 2009.

[7] L. C. H. Fernald, "Socio-economic status and body mass index in low-income Mexican adults," Social Science and Medicine, vol. 64, no. 10, pp. 2030-2042, 2007.

[8] L. M. Gomez, B. Hernández-Prado, C. Morales Mdel, and T. Shamah-Levy, "Physical activity and overweight/obesity in adult Mexican population. The Mexican National Health and Nutrition Survey 2006," Salud Publica de Mexico, vol. 51, supplment 4, pp. S621-S629, 2009.

[9] L. C. Fernald, J. P. Gutierrez, L. M. Neufeld et al., "High prevalence of obesity among the poor in Mexico," Journal of the American Medical Association, vol. 291, no. 21, pp. 25442545, 2004.

[10] S. Barquera, L. Hernández-Barrera, I. Campos-Nonato et al., "Energy and nutrient consumption in adults: analysis of the Mexican National Health and Nutrition Survey 2006," Salud pública de México, vol. 51, pp. S562-573, 2009.

[11] G. Olaiz, J. Rivera, T. Shamah et al., Encuesta Nacional de Salud y Nutrición 2006, Instituto Nacional de Salud Pública, Cuernavaca, México, 2006.

[12] The World Bank, "Income generation and social protection for the poor," in Income Generation and Social Protection for the Poor, The World Bank, Washington, DC, USA, 2005.

[13] S. G. Sosa-Rubí, O. Galárraga, and R. López-Ridaura, "Diabetes treatment and control: the effect of public health insurance for the poor in Mexico," Bulletin of the World Health Organization, vol. 87, no. 7, pp. 512-519, 2009.

[14] M. Acosta-Mendez, L. Mariscal-Servitje, and C. SantosBurgoa, "The present and future of Mexican health promotion," Promotion \& Education, vol. 14, no. 4, pp. 224-227, 2007.

[15] J. B. Anderson and J. Gerber, Fifty Years of Change on the U.S.-Mexico Border: Growth, Development and Quality of Life, University of Texas Press, Austin, Tex, USA, 2007.

[16] S. Barquera, C. Hotz, and J. Rivera, "Food consumption, food expenditure, anthropometric status and nutrition-related diseases in Mexico," in The Double Burden of Malnutrition: Case Studies from Six Developing Countries, Food and Agriculture Organization of the United Nations, Ed., pp. 161-203, Food and Agriculture Organization of the United Nations, Rome, Italy, 2006.

[17] J. A. Rivera, S. Barquera, F. Campirano, I. Campos, M. Safdie, and V. Tovar, "Epidemiological and nutritional transition in Mexico: rapid increase of non-communicable chronic diseases and obesity," Public Health Nutrition A, vol. 5, no. 1, pp. 113$122,2002$.

[18] J. A. Rivera, S. Barquera, T. González-Cossío, G. Olaiz, and J. Sepúlveda, "Nutrition transition in Mexico and in other Latin American countries," Nutrition Reviews, vol. 62, no. 7, pp. S149-S157, 2004.

[19] A. M. Buttenheim, R. Wong, N. Goldman, and A. R. Pebley, "Does social status predict adult smoking and obesity? Results 
from the 2000 Mexican national health survey," Global Public Health, vol. 5, no. 4, pp. 413-426, 2010.

[20] B. Galobardes, M. Shaw, D. A. Lawlor, G. D. Smith, and J. Lynch, "Indicators of socioeconomic position," in Methods in Social Epidemiology, J. M. Oakes and J. S. Kaufman, Eds., pp. 47-85, Jossey-Bass, San Francisco, Calif, USA, 2006.

[21] The World Bank, Poverty in Mexico: An Assessment of Trends, Conditions, and Government Strategy, The World Bank, Washigton, DC, USA, 2004.

[22] A. M. Valle, "Social class, marginality and self-assessed health: a cross-sectional analysis of the health gradient in Mexico," International Journal for Equity in Health, vol. 8, article 3, 2009.

[23] S. F. Reardon, " conceptual framework for measuring segregation and its association with population outcomes," in Methods in Social Epidemiology, J. M. Oakes and J. S. Kaufman, Eds., pp. 169-192, Jossey-Bass, San Francisco, Calif, USA, 2006.

[24] B. M. Popkin and P. Gordon-Larsen, "The nutrition transition: worldwide obesity dynamics and their determinants," International Journal of Obesity, vol. 28, supplement 3, pp. S2S9, 2004.

[25] D. Williams, "Patterns and causes of disparities in health," in Policy Challenges in Modern Health Care, D. Mechanic, L. B. Rogut, and D. C. Colby, Eds., pp. 115-134, Rutgers University Press, New Brunswick, NJ, USA, 2005.

[26] I. B. Grafova, V. A. Freedman, R. Kumar, and J. Rogowski, "Neighborhoods and obesity in later life," American Journal of Public Health, vol. 98, no. 11, pp. 2065-2071, 2008.

[27] P. Verger, B. Saliba, V. Guagliardo, A. D. Bouhnik, and S. Eichenbaum-Voline, "Individual social characteristics, municipal environment and the prevalence of weight problems in early childhood: a multilevel analysis," Revue d'Epidemiologie et de Sante Publique, vol. 55, no. 5, pp. 347-356, 2007.

[28] T. King, A. M. Kavanagh, D. Jolley, G. Turrell, and D. Crawford, "Weight and place: a multilevel cross-sectional survey of area-level social disadvantage and overweight/obesity in Australia," International Journal of Obesity, vol. 30, no. 2, pp. 281-287, 2006.

[29] J. P. Habicht, "Standardization of quantitative epidemiological methods in the field," Boletin de la Oficina Sanitaria Panamericana, vol. 76, no. 5, pp. 375-384, 1974.

[30] L. F. Lopez-Calva, L. Rodriguez-Chamussy, and M. Szekely, "Poverty maps and public policy in Mexico," in More than a Pretty Picture: Using Policy Maps to Design Better Policies and Interventions, T. Bedi, A. Coudouel, and K. Simler, Eds., pp. 188-207, The World Bank, Washington, DC, USA, 2007.

[31] S. Peña, "Recent developments in urban marginality along Mexico's northern border," Habitat International, vol. 29, no. 2, pp. 285-301, 2005.

[32] D. Bates, M. Maechler, and B. Bolker, lme4: linear mixedeffects models using S4 classes. 2011.

[33] R Development Core Team, R: A Language and Environment for Statistical Computing, R Foundation for Statistical Computing, Vienna, Austria, 2012.

[34] A. C. Carle, "Fitting multilevel models in complex survey data with design weights: recommendations," BMC Medical Research Methodology, vol. 9, no. 1, article 49, 2009.

[35] M. Monteverde, K. Noronha, A. Palloni, and B. Novak, "Obesity and excess mortality among the elderly in the United States and Mexico," Demography, vol. 47, no. 1, pp. 79-96, 2010.

[36] M. Pena and J. Bacallao, "Obesity among the poor: an emerging problem in Latin America and the Caribbean," in Obesity and Poverty: A New Public Health Challenge, M.
Pena and J. Bacallao, Eds., pp. 3-10, Pan American Health Organization, Washington, DC, USA, 2000.

[37] S. Barquera, L. Hernandez-Barrera, M. L. Tolentino et al., "Energy intake from beverages is increasing among Mexican adolescents and adults," Journal of Nutrition, vol. 138, no. 12, pp. 2454-2461, 2008.

[38] A. Jimenez-Aguilar, M. Flores, and T. Shamah-Levy, "Sugarsweetened beverages consumption and BMI in Mexican adolescents. Mexican National Health and Nutrition Survey 2006," Salud Publica de Mexico, vol. 51, supplement 4, pp. S604-S612, 2009.

[39] N. Moise, E. Cifuentes, E. Orozco, and W. Willett, "Limiting the consumption of sugar sweetened beverages in Mexico's obesogenic environment: a qualitative policy review and stakeholder analysis," Journal of Public Health Policy, vol. 32, no. 4, pp. 458-475, 2011.

[40] J. A. Rivera, O. Muñoz-Hernández, M. Rosas-Peralta, C. A. Aguilar-Salinas, B. M. Popkin, and W. C. Willett, "Drink consumption for a healthy life: recommendations for the general population in Mexico," Gaceta médica de México, vol. 144, no. 5, pp. 369-388, 2008.

[41] L. E. Bautista, J. P. Casas, V. M. Herrera et al., "The Latin American Consortium of Studies in Obesity (LASO)," Obesity Reviews, vol. 10, no. 3, pp. 364-370, 2009.

[42] L. M. Neufeld, S. Hernández-Cordero, L. C. Fernald, and U. Ramakrishnan, "Overweight and obesity doubled over a 6year period in young women living in poverty in Mexico," Obesity, vol. 16, no. 3, pp. 714-717, 2008.

[43] N. Almeida-Filho, I. Lessa, L. Magalhães et al., "Social inequality and depressive disorders in Bahia, Brazil: Interactions of gender, ethnicity, and social class," Social Science and Medicine, vol. 59, no. 7, pp. 1339-1353, 2004.

[44] M. Bronfman, "Infant mortality and crisis in Mexico," International Journal of Health Services, vol. 22, no. 1, pp. 157-167, 1992.

[45] R. Lozano, B. Zurita, F. Franco, T. Ramirez, P. Hernandez, and J. L. Torres, "Mexico: marginality, need and resource allocation at the county level," in Challenging Inequities in Health: From Ethics to Action, T. Evans, M. Whitehead, F. Diderichsen, A. Bhuiya, and M. Wirth, Eds., pp. 276-295, Oxford University Press, Oxford, UK, 2001.

[46] E. Bastida and G. A. Soydemir, "Obesity and employment as predictors of diabetes in Mexican Americans: findings from a longitudinal study," Applied Economics, vol. 41, no. 20, pp. 2533-2540, 2009.

[47] A. Bersamin, K. D. Hanni, and M. A. Winkleby, "Predictors of trying to lose weight among overweight and obese MexicanAmericans: a signal detection analysis," Public Health Nutrition, vol. 12, no. 1, pp. 64-73, 2009.

[48] S. E. Colby, S. Morrison, and L. Haldeman, "What changes when we move? A transnational exploration of dietary acculturation," Ecology of Food and Nutrition, vol. 48, no. 4, pp. 327343, 2009.

[49] U. Colón-Ramos, F. E. Thompson, A. L. Yaroch et al., "Differences in fruit and vegetable intake among hispanic subgroups in California: results from the 2005 California Health Interview Survey," Journal of the American Dietetic Association, vol. 109, no. 11, pp. 1878-1885, 2009.

[50] N. Kaushal, "Adversities of acculturation? Prevalence of obesity among immigrants," Health Economics, vol. 18, no. 3, pp. 291-303, 2009.

[51] R. Pérez-Escamilla and P. Putnik, "The role of acculturation in nutrition, lifestyle, and incidence of type 2 diabetes among 
Latinos," Journal of Nutrition, vol. 137, no. 4, pp. 860-870, 2007.

[52] P. J. Salsberry and P. B. Reagan, "Comparing the influence of childhood and adult economic status on midlife obesity in Mexican American, white, and African American women: populations at risk across the lifespan: population studies," Public Health Nursing, vol. 26, no. 1, pp. 14-22, 2009.

[53] J. A. Skelton, S. R. Cook, P. Auinger, J. D. Klein, and S. E. Barlow, "Prevalence and trends of severe obesity among US children and adolescents," Academic Pediatrics, vol. 9, no. 5, pp. 322-329, 2009. 


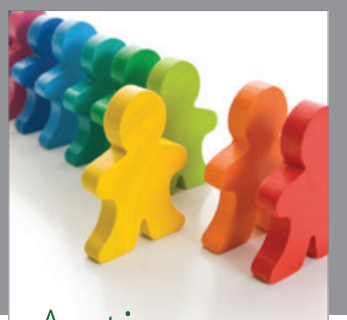

Autism

Research and Treatment
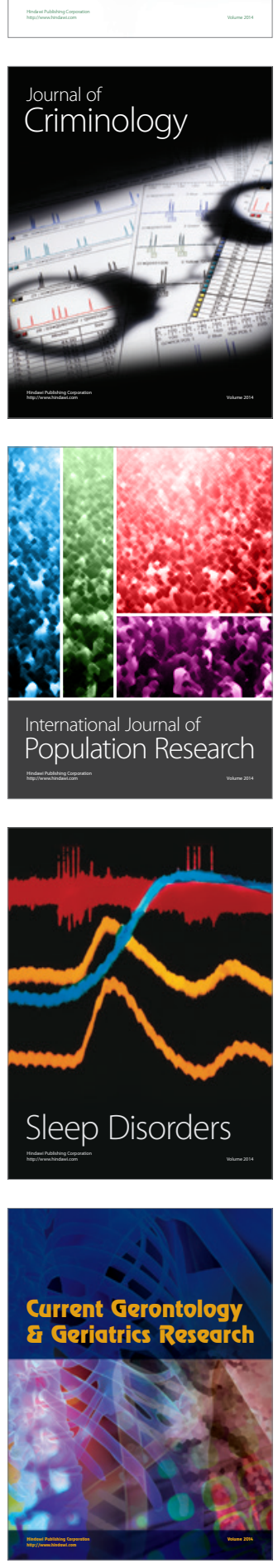
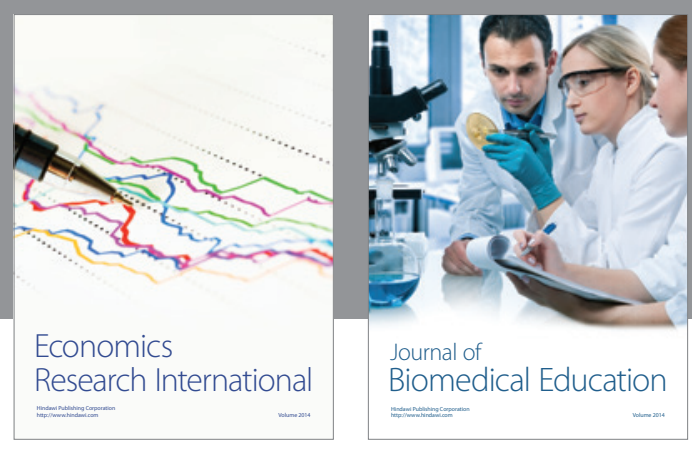

Journal of

Biomedical Education

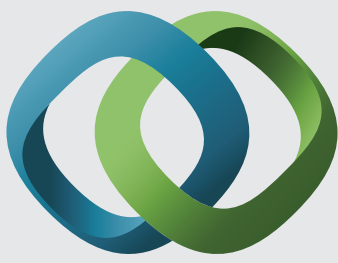

\section{Hindawi}

Submit your manuscripts at

http://www.hindawi.com
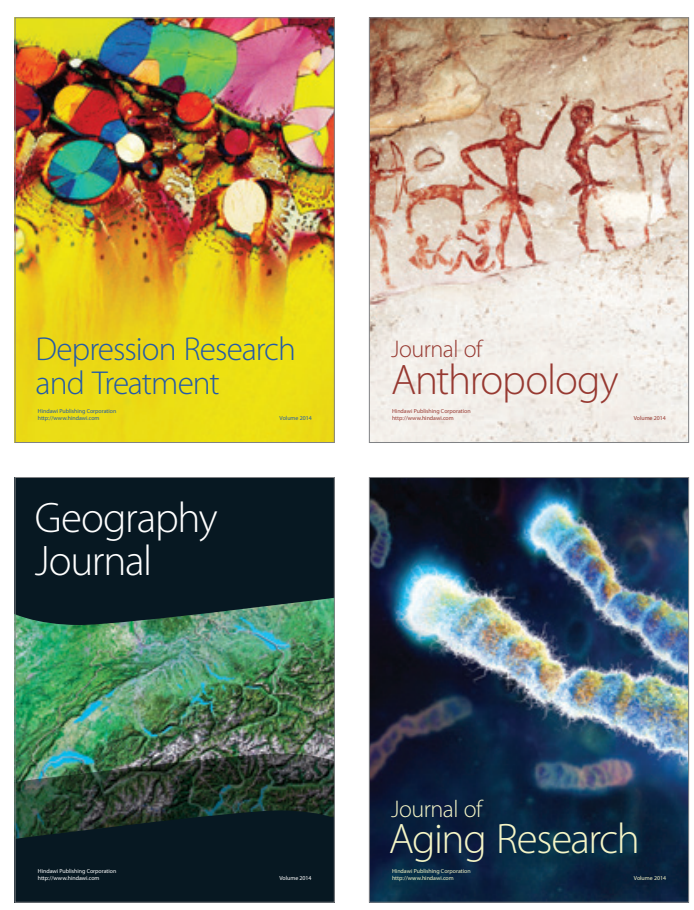

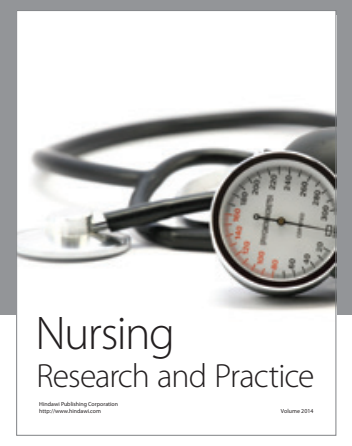

Nursing

Research and Practice

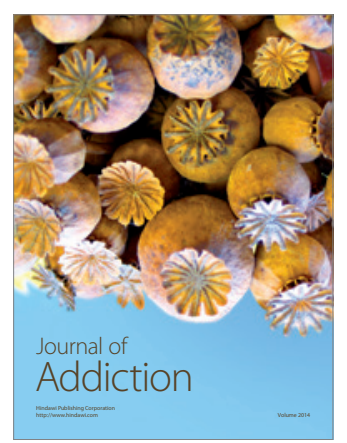

Child Development

Research

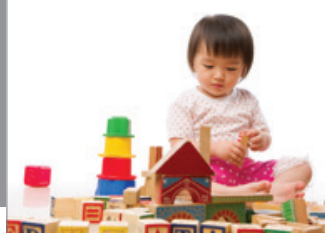

迥
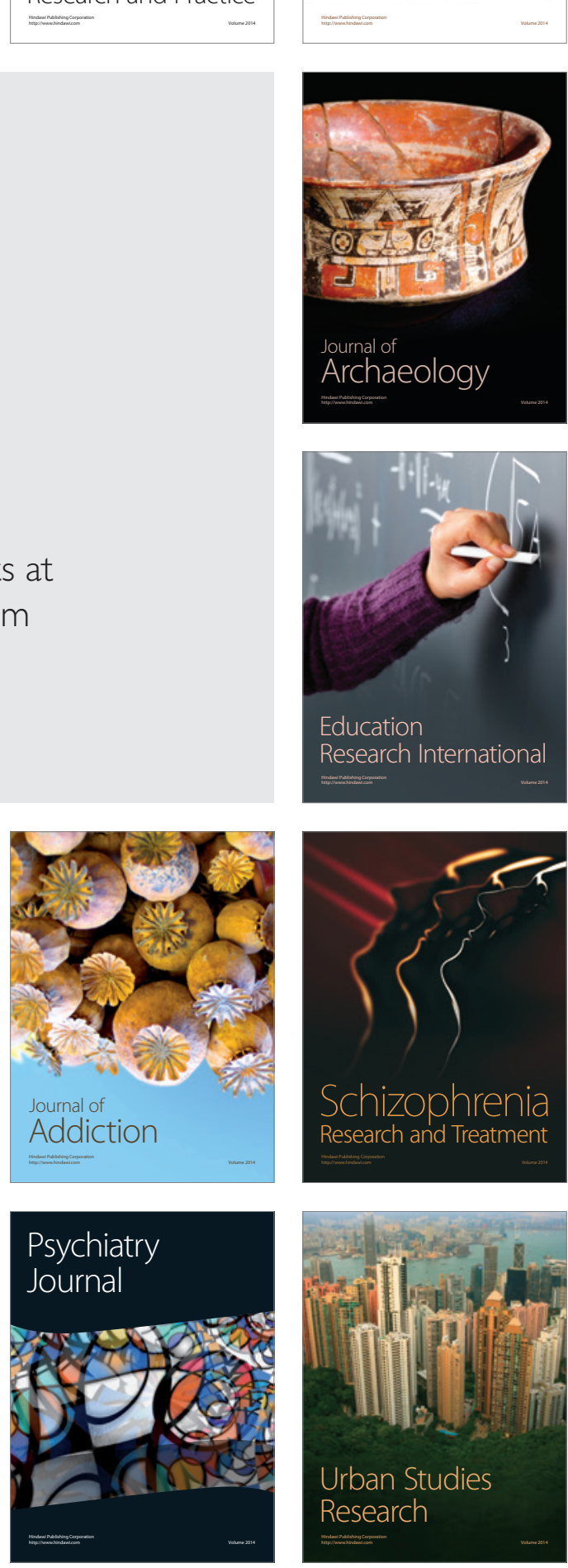